\title{
Validity and Reliability of an Information-Motivation-Skill-Behavior Questionnaire: A Gender-Sensitive HIV Survey
}

\author{
Sara Ahsani-Nasab, Minoo Mohraz, Negin Abedinzadeh, Hanieh Golchehregan, \\ Mona Mohammadi-Firouzeh, Sara Sardashti* \\ Iranian Research Center for HIV/AIDS, Iranian Institute for Reduction of High Risk Behaviors, Tehran University \\ of Medical Sciences, Tehran, Iran \\ Email: "sarasardashti@gmail.com, ${ }^{*}$ s-sardashti@farabi.tums.ac.ir
}

Received 18 April 2016; accepted 5 June 2016; published 8 June 2016

Copyright (C) 2016 by authors and Scientific Research Publishing Inc.

This work is licensed under the Creative Commons Attribution International License (CC BY). http://creativecommons.org/licenses/by/4.0/

(c) (i) Open Access

\section{Abstract}

Background: Despite the essence of HIV-related surveys, their precision in measurement of intended constructs has been an area of controversy. Considering the increasing trend of sexual transmission of HIV among women, standard gender-sensitive tools can yield pivotal information for researchers and policy-makers in Iran. Aim: To evaluate the reliability and validity of a questionnaire (IMSB) based on the Information-Motivation-Behavior model of HIV-related behavior prediction. Methods: The IMSB survey constituted of five main domains: HIV-related knowledge, attitudes toward people living with HIV, motivation to practice safe-sex, skills to practice safe-sex, and HIV-related behaviors. Completed questionnaires $(n=189)$ from pilot phases of three projects were accessed. We assessed face and content validity through expert consultation and respondent feed-backs for the primary pool of items. Discriminant validity was measured utilizing non-parametric tests. Cronbach's alpha was calculated for each domain to assess internal consistency, and paired t-tests were used to measure stability over time. Results: The primary pool of items was reduced in the process of validation. The discriminant validity was appraised to be favorable since the survey can differentiate between age groups, women with different levels of education and marital status. The survey was reliable in 4 domains; but a Cronbach's alpha of 0.6 was reported for the fifth domain (HIV-related behaviors). Younger women had higher knowledge and motivation scores; single women were more motivated to practice safe-sex and divorced/widowed women had lower motivation and skills scores. Conclusion: This questionnaire can be used as a valid and reliable tool to measure the IMB constructs. The lower reliability of the "behavior" domain is probably rooted in societal norms and cultural definitions. The integration of motivation and skill domains can provide valuable information for clinicians/interventionists to address

${ }^{*}$ Corresponding author.

How to cite this paper: Ahsani-Nasab, S., Mohraz, M., Abedinzadeh, N., Golchehregan, H., Mohammadi-Firouzeh, M. and Sardashti, S. (2016) Validity and Reliability of an Information-Motivation-Skill-Behavior Questionnaire: A Gender-Sensitive HIV Survey. World Journal of AIDS, 6, 47-53. http://dx.doi.org/10.4236/wja.2016.62007 
vulnerabilities experienced by their female clients.

\author{
Keywords
}

\author{
Sexual Behavior, Reliability and Validity, HIV, Women
}

\title{
1. Introduction
}

Despite substantial progress in understanding the global HIV epidemic, knowledge on the epidemic in the Middle East and North Africa (MENA) is comparatively limited [1]. Between 2001 and 2012, the number of new HIV diagnoses in MENA grew by 52 percent, the most rapid increase among world regions [1] [2]. In most countries of the region including Iran the epidemic is concentrated among high-risk groups [2]; and much of the existing literature on their profile of risk is based on the results of bio-behavioral surveys and investigational studies that focus on HIV knowledge, attitudes toward safe-sex and self-reports of sexual behavior [1] [3].

Although injection drug users (IDUs) constituted the largest group to be affected in Iran a decade ago, sexual transmission has been on the rise in recent years and women are more vulnerable to HIV/AIDS than ever before [3]. Hence, understanding sexual behavior, determinants of involvement in safe-sex, and barriers on the way of protective behavior among women are critical in development of future preventive interventions [4].

Different socio-cognitive models explain the dynamics of sexual behavior and predict intentions to participate in safe-sex [5]; these models are applied to design questionnaires and interventions to evaluate and promote safe-sex [5]. Information-Motivation-Behavioral Skills (IMB) is the framework most commonly applied to behavior change in the field of HIV/AIDS [6]-[9]. IMB postulates that knowledge about HIV is essential in decision-making and motivates people to commit to safe sexual practices; but above all behavioral skills are imperative for behavior change [5] [9].

Previous studies among at-risk or HIV infected women in Iran suggest that knowledge on HIV does not necessarily lead to behavior change, hence more emphasis should be put on socio-cultural factors that affect women's behavior [10] [11]. Stigma and discrimination cause most-at-risk women to avoid HIV testing and to seek the treatment and support they need [3]. Accordingly, access to reliable and accurate information to understand the interactions between women's HIV-related knowledge, their attitudes toward people living with HIV (PLWH), their motivation and skills to practice safe-sex and finally their sexual behavior can improve efforts to develop effective safe-sex promotion programs [9] [11]. Biological and behavioral surveillance surveys (BBSS) concerning HIV are often used to inform and evaluate HIV prevention programs. However, the reliability and validity of utilized questionnaires for the behavioral component of these surveys is rarely considered.

We aimed to assess reliability and validity of a safe-sex questionnaire specifically designed for women at risk of HIV/AIDS in Iran based on the IMB model. The questionnaire is made up of five main constructs: HIV-related knowledge, attitudes toward PLWH, motivation to practice safe-sex, skills to practice safe-sex, and HIVrelated behaviors.

\section{Methods}

\subsection{Participants}

To achieve the purposes of the present study, we accessed questionnaires from previous studies conducted among girls/women ( $\geq 15$ years old). Three groups of women had been recruited including: at-risk youth, wives of imprisoned men, and a group of high-school educators. The re-known standard for reliability assessment is at least 15 or 20 subjects per domain. So a minimum sample size of 75 was to be considered for this study. Through careful evaluation of the ongoing projects at our center, we enrolled 127 women through pre-filled questionnaires. Overall, we utilized189 questionnaires in data analysis, double surveys were filled by a group of respondents.

\subsection{Measures}

The questionnaire used in the present study consisted of five major domains: a) HIV-related knowledge; b) attitudes toward PLWH; c) motivation to practice safe-sex; d) skills to practice safe-sex (including 2 sub-domains: 
perceived difficulty of AIDS preventive behaviors, perceived effectiveness of AIDS preventive behaviors); and e) HIV-related behaviors. The items for each sub-scale had been extracted from a pool of items utilized in previous studies [12]-[16] or from surveys previously validated in research works published by other Persian speaking researchers [10] [17]-[20]. We carefully evaluated the primary pool of items and further assessed the five domains as explained below:

Reliability

We measured two constructs of reliability;

- Internal consistency: Cronbach’s alpha was calculated, values over 0.6 were considered as "acceptable". Values between 0.7 and 0.79 were interpreted as "good" and values over 0.8 were interpreted as "excellent" internal consistency [21].

- Consistency over time (stability): paired t-test was conducted to evaluate repeatability of measures over time. A group of respondents had re-filled questionnaires at a one month interval and the data driven from their surveys were used at this stage of analysis.

Validity

- Face and content validity: To appraise face validity, we interviewed 10 women were regarding the apprehensiveness of the items. We noted any difficulty in understanding the questions and acted upon their feedbacks to implement necessary corrections. Drafted questionnaire was sent to eight experts in the field and their comments were discussed in a separate session. Further modifications were made to the final questionnaire.

- Discriminant validity: We assessed discriminant validity utilizing Mann-Whitney U test or Kruskal-Wallis test. The scores in different sub-scales were compared along different subgroups of age, education, and marital status.

\subsection{Ethical Considerations}

Data were extracted from pre-filled questionnaires from previous studies approved by the Review Boards of the Iranian Research Center for HIV/AIDS, Tehran University of Medical Sciences. All questionnaires were anonymous and all the data sheets were kept confidential.

\section{Results}

In total, we accessed 189 completed questionnaires (considering re-test questionnaire). We analyzed data driven from 127 questionnaires to assess internal consistency; 124 questionnaires were used to evaluate consistency over time (stability), and 92 questionnaires were analyzed to investigate discriminant validity.

\subsection{General Characteristics}

The mean age of the respondents to the questionnaires was calculated to be 29.79 (SD = 11.57) years. Other demographic features are shown in Table 1.

\section{Table 1. General and demographic characteristics of study participants $(\mathrm{N}=127)$.}

\begin{tabular}{ccc}
\hline Variable & Frequency & Percentage \\
\hline Age (year) & & 23.6 \\
$15-20$ & 30 & 38.6 \\
$21-30$ & 49 & 37.8 \\
$>30$ & 48 & 28.4 \\
Education & & 35.4 \\
Under diploma & 36 & 36.2 \\
Diploma & 45 & 51.2 \\
Higher diploma & 46 & 44.1 \\
Marital status & & 4.7 \\
Single & 65 & 56 \\
Married & 66 & \\
Divorced/Widowed
\end{tabular}




\subsection{Reliability Measures}

Internal consistency: We calculated Cronbach's alpha for the six domains of the questionnaire ("skills" had two sub-domains). All domains showed acceptable internal consistency (knowledge: 0.89, attitude: 0.71, motivation: 0.84, perceived effectiveness of AIDS preventive behavior: 0.90) except for "perceived difficulty of AIDS preventive behaviors" (alpha: 0.62) and "HIV-related behaviors" (alpha: 0.60).

Consistency over time: To evaluate stability and repeatability, we performed paired t-tests on two sets of data driven from initial and repeated surveys from 62 respondents. For five domains, mean scores at time 1 and time 2 showed no significant difference hence stability of the questionnaire was confirmed over time (Table 2).

\subsection{Validity}

Face and content validity: A pool of items had been used to design the draft survey. The initial format constituted of 143 items; after consultation with experts, we reduced items to 102 in six main domains. Then the questionnaire was distributed among 10 random female respondents and another 27 items were omitted after primary analysis of data and authors' modifications. The final questionnaire had 75 items: 30 items for "HIV-related knowledge", 17 items for "attitudes toward PLWH", nine items for "motivation to practice safe-sex", 10 items for "skills to practice safe-sex", and nine items for "HIV-related behaviors".

Discriminant validity: We compared mean scores in various domains between different subgroups based on their age (<20, $21-30,>30$ ), level of education (not finished high-school, finished high-school, college/higher education), and marital status (single, married, divorced/widowed). Table 3 shows that the questionnaire can differentiate between various subgroups of respondents.

Table 2. Test re-test reliability measures $(\mathrm{N}=62)$.

\begin{tabular}{ccccc}
\hline Domain & $\begin{array}{c}\text { Time 1 score } \\
\text { Mean (SD) }\end{array}$ & $\begin{array}{c}\text { Time 2 score } \\
\text { Mean (SD) }\end{array}$ & $\begin{array}{c}\text { (Time 2 - Time 1) } \\
\text { score Mean (SD) }\end{array}$ & $p$-value \\
\hline Knowledge & $22.19(5.3)$ & $22.50(6.7)$ & $0.31(6.6)$ & 0.715 \\
Attitude & $12.08(2.8)$ & $11.82(3.6)$ & $-0.26(3.9)$ & 0.606 \\
Motivation & $21.96(6.4)$ & $21.75(7.2)$ & $-0.21(8.5)$ & 0.867 \\
Safe-sex skills & & & \\
Perceived difficulty of & $10.23(2.3)$ & $10.44(2.7)$ & $0.21(2.9)$ & 0.619 \\
AIDS preventive behaviors & & & \\
Perceived effectiveness of & $11.0(3.5)$ & $10.77(3.6)$ & $-0.23(3.7)$ & 0.659 \\
AIDS preventive behaviors & & & & \\
\hline
\end{tabular}

${ }^{\mathrm{a}}$ Significance level $=0.05$.

Table 3. Discriminant validity for main domains of the questionnaire $(\mathrm{N}=92)$.

\begin{tabular}{|c|c|c|c|c|c|c|c|c|c|c|c|c|}
\hline & \multicolumn{3}{|c|}{ Age } & \multirow[t]{2}{*}{$p$-value ${ }^{a}$} & \multicolumn{3}{|c|}{ Marital status } & \multirow[t]{2}{*}{$p$-value } & \multicolumn{3}{|c|}{ Education } & \multirow[t]{2}{*}{$p$-value } \\
\hline & $15-20$ & $21-30$ & $>30$ & & Single & Married & $\begin{array}{l}\text { Divorced/ } \\
\text { Widowed }\end{array}$ & & $\begin{array}{c}\text { Under } \\
\text { diploma }\end{array}$ & Diploma & $\begin{array}{l}\text { Higher } \\
\text { diploma }\end{array}$ & \\
\hline Knowledge; mean (SD) & $\begin{array}{l}22.03 \\
(5.9)\end{array}$ & $\begin{array}{l}20.87 \\
(5.2)\end{array}$ & $\begin{array}{c}16.33 \\
(4.9)\end{array}$ & 0.001 & $\begin{array}{l}21.82 \\
(5.5)\end{array}$ & $\begin{array}{l}19.27 \\
(4.7)\end{array}$ & $\begin{array}{l}12.83 \\
(4.8)\end{array}$ & $<0.001$ & $\begin{array}{l}18.97 \\
(7.1)\end{array}$ & $\begin{array}{l}21.7 \\
(4.4)\end{array}$ & $\begin{array}{l}21.18 \\
(3.3)\end{array}$ & 0.326 \\
\hline Attitude; mean (SD) & $\begin{array}{l}12.40 \\
(3.2)\end{array}$ & $\begin{array}{l}11.6 \\
(2.7)\end{array}$ & $\begin{array}{l}10.67 \\
(3.8)\end{array}$ & 0.172 & $\begin{array}{l}11.98 \\
(2.9)\end{array}$ & $\begin{array}{l}11.58 \\
(3.2)\end{array}$ & $\begin{array}{c}9.5 \\
(4.7)\end{array}$ & 0.465 & $\begin{array}{l}11.03 \\
(3.9)\end{array}$ & $\begin{array}{l}12.14 \\
(2.3)\end{array}$ & $\begin{array}{l}12.36 \\
(2.8)\end{array}$ & 0.507 \\
\hline Motivation; mean (SD) & $\begin{array}{c}21.44 \\
(6.7)\end{array}$ & $\begin{array}{l}25.41 \\
(8.6)\end{array}$ & $\begin{array}{r}27.07 \\
(9.9)\end{array}$ & 0.119 & $\begin{array}{l}22.04 \\
(7.3)\end{array}$ & $\begin{array}{l}27.76 \\
(8.9)\end{array}$ & $\begin{array}{r}33.17 \\
(7.1)\end{array}$ & 0.001 & $\begin{array}{c}27 \\
(8.9)\end{array}$ & $\begin{array}{c}22.95 \\
(7.8)\end{array}$ & $\begin{array}{r}22.27 \\
(7.7)\end{array}$ & 0.141 \\
\hline \multicolumn{13}{|l|}{ Safe-sex skills } \\
\hline $\begin{array}{l}\text { Perceived difficulty of } \\
\text { AIDS preventive } \\
\text { behaviors; mean (SD) }\end{array}$ & $\begin{array}{l}10.45 \\
(2.3)\end{array}$ & $\begin{array}{l}10.1 \\
(2.9)\end{array}$ & $\begin{array}{l}9.07 \\
(3.9)\end{array}$ & 0.556 & $\begin{array}{l}9.93 \\
(2.4)\end{array}$ & $\begin{array}{l}10.68 \\
(3.4)\end{array}$ & $\begin{array}{c}8.5 \\
(4.4)\end{array}$ & 0.293 & $\begin{array}{c}9.8 \\
(3.5)\end{array}$ & $\begin{array}{l}9.75 \\
(2.4)\end{array}$ & $\begin{array}{l}11.91 \\
(1.4)\end{array}$ & 0.039 \\
\hline $\begin{array}{l}\text { Perceived effectiveness } \\
\text { of AIDS preventive } \\
\text { behaviors; mean (SD) }\end{array}$ & $\begin{array}{l}11.14 \\
(3.6)\end{array}$ & $\begin{array}{l}13.17 \\
(5.2)\end{array}$ & $\begin{array}{l}15.07 \\
(6.3)\end{array}$ & 0.115 & $\begin{array}{l}11.72 \\
(4.1)\end{array}$ & $\begin{array}{l}14.31 \\
(5.7)\end{array}$ & $\begin{array}{l}17.17 \\
(7.7)\end{array}$ & 0.061 & $\begin{array}{c}14.81 \\
(5.8)\end{array}$ & $\begin{array}{l}11.45 \\
(4.2)\end{array}$ & $\begin{array}{l}11.45 \\
(3.6)\end{array}$ & 0.021 \\
\hline
\end{tabular}

${ }^{\mathrm{a}}$ Significance level $=0.05$. 


\section{Discussion}

We assessed the reliability and validity of a self-report IMSB questionnaire among women. In the course of the study, we modified and improved the survey and came up with a final tool adjusted based on the IMB model. IMB is the socio-cognitive model most frequently utilized to predict HIV-related sexual behaviors [9]. The Persian version of the current questionnaire has proven to be reliable and valid in measurement of the different domains of HIV-related information, motivation, behavioral skills and behavior in our study population.

Size and homogeneity of the sample with regards to their gender is a strength for the present study. Women are physiologically more vulnerable to HIV and other STDs while contextual factors including gender norms prominently influence their sexual behavior [22]. Social factors affecting the process of decision-making to practice safe-sex is an area of under representation in the literature from MENA region [10]. The assessment of motivation and behavioral skills for safe-sex practice in the present study yields valuable information for interventional scientists to develop gender-specific surveys and educational materials. Three different groups of women at various levels of risk for contracting HIV were evaluated in this study hence the questionnaire can be applied to different sub-populations.

The limitation of the current questionnaire was in the reliability of the HIV-related behaviors domain (Cronbach's alpha $=0.6$ ), although we had reduced the sample size by excluding the missing data and had omitted many of the questions through validation. On the other side, the majority of excluded cases were single/unmarried women. An explanation to this finding could be the effect of cognitive and situational factors that influence response generation [23]. Other than recall biases, social values may interfere with the "decision-making" step of the cognitive process through which the respondent reports a specific behavior [24]. Gender norms accepted in the society could lead women to underreport their risk behaviors as observed in the current study [24]. We assume that the method of administration of the questionnaire has probably had subtle effect in lowering the reliability as current evidence has not proven superiority of technology based systems or face-to-face interview compared to self-administered surveys [25].

In the evaluation of discriminant validity, we found that women with higher levels of education had lower perceived difficulty and higher perceived effectiveness to practice safe sex. Motivation to practice safe-sex was higher among single respondents while the lowest for clients who were either divorced or widowed. Moreover, younger women had higher knowledge levels and most of them were single and reported no sexual contacts. We suggest several explanations for these findings: 1) younger and single respondents had higher knowledge levels hence more motivated and empowered to practice safe-sex; 2) pre-marital sex being highly prohibited could play a two-way role: single women may over-report motivation because they are expected to (social desirability); or they may overestimate their motivation not having experienced actual encounters; 3) widowed or divorced participants may be unwilling to seek information due to lower perceived risk (not studied here) compared to married or single women, hence less motivated to practice safe-sex.

Based on the findings of this study, we suggest that the current IMSB questionnaire is valid and reliable for research/survey purposes. The integration of motivation and skill domains in this questionnaire has yielded valuable information that could be implemented in design of gender-sensitive interventions. However, the low reliability of behavior domain highlights the importance of behavioral surveys at national level where biological markers are utilized to re-check precision. The results of such country-level studies could also help with evaluation of cost-effectiveness of STD/HIV clinics to be established throughout the country.

\section{Acknowledgements}

This study was supported by the Tehran University of Medical Sciences.

\section{References}

[1] United Nations Joint Program for HIV/AIDS (UNAIDS) (2014) The Gap Report. http://www.unaidsmena.org/sitefiles/reportlang files/en/pic 54.pdf

[2] Middle East and North Africa Harm Reduction Association. MENAHRA Strategic Plan 2014-2019. http://www.menahra.org/en/menahra-publications/publications

[3] UNAIDS and the Ministry of Health and Medical Education. I.R. Iran Country Progress Repost 2015. http://www.unaids.org/sites/default/files/en/dataanalysis/knowyourresponse/countryprogressreports/2014countries/IRN narrative_report_2014_en.pdf 
[4] Lotfi, R., Tehrani, F.R., Yaghmaei, F. and Hajizadeh, E. (2012) Barriers to Condom Use among Women at Risk of HIV/AIDS: A Qualitative Study from Iran. BMC Women's Health, 12, 13. http://dx.doi.org/10.1186/1472-6874-12-13

[5] Espada, J.P., Morales, A., Guillén-Riquelme, A., Ballester, R. and Orgilés, M. (2016) Predicting Condom Use in Adolescents: A Test of Three Socio-Cognitive Models Using a Structural Equation Modeling Approach. BMC Public Health, 16, 35.

[6] Fisher, J.D. and Fisher, W.A. (1992) Changing AIDS-Risk Behavior. Psychological Bulletin, 111, 455-474. http://dx.doi.org/10.1037/0033-2909.111.3.455

[7] Fisher, J.D., Fisher, W.A., Williams, S.S. and Malloy, T.E. (1994) Empirical Tests of an Information-MotivationBehavioral Skills Model of AIDS-Preventive Behavior with Gay Men and Heterosexual University Students. Health Psychology, 13, 238-250. http://dx.doi.org/10.1037/0278-6133.13.3.238

[8] Fisher, W.A., Williams, S.S., Fisher, J.D. and Malloy, T.E. (1999) Understanding AIDS Risk Behavior among Sexually Active Urban Adolescents: An Empirical Test of the Information-Motivation-Behavioral Skills Model. AIDS and Behavior, 3, 13-23. http://dx.doi.org/10.1023/A:1025411317851

[9] Fisher, J.D. and Fisher WA. (2002) The Information-Motivation-Behavioral Skills Model. Emerging Theories in Health Promotion Practice and Research: Strategies for Improving Public Health, 1, 40-70.

[10] Lotfi, R., Tehrani, F.R., Khoei, E.M., Yaghmaei, F. and Dworkin, S.L. (2013) How Do Women at Risk of HIV/AIDS in Iran Perceive Gender Norms and Gendered Power Relations in the Context of Safe Sex Negotiations? Archives of Sexual Behavior, 42, 873-881. http://dx.doi.org/10.1007/s10508-012-0040-6

[11] Lotfi, R., Tehrani, F.R., Yaghmaei, F. and Hajizadeh, E. (2014) Developing a Valid and Reliable Instrument to Predict the Protective Sexual Behaviors in Women at Risk of Human Immunodeficiency Virus. Iranian Red Crescent Medical Journal, 16, Article ID: e14682. http://dx.doi.org/10.5812/ircmj.14682

[12] Jafari, A., Yazdani, R., Khami, M.R., Mohammadi, M. and Hajiabdolbaghi, M. (2012) Effect of an Educational Course at an Iranian Dental School on Students' Knowledge of and Attitudes about HIV/AIDS. Journal of Dental Education, 76, 792-799.

[13] Moayedi-Nia, S., BayatJozani, Z., EsmaeeliDjavid, G., Entekhabi, F., Bayanolhagh, S., Saatian, M., Sedaghat, A., Nikzad, R., Jahanjoo Aminabad, F. and Mohraz, M. (2016) HIV, HCV, HBV, HSV, and Syphilis Prevalence among Female Sex Workers in Tehran, Iran, by Using Respondent-Driven Sampling. AIDS Care, 28, 487-490. http://dx.doi.org/10.1080/09540121.2015.1109582

[14] Misovich, S.J., Fisher, W.A. and Fisher, J.D. (1998) A Measure of AIDS Prevention Information, Motivation, Behavioral Skills, and Behavior. Handbook of Sexuality-Related Measures, 328-337.

[15] Hajiabdolbaghi, M., Razani, N., Karami, N., Kheirandish, P., Mohraz, M., Rasoolinejad, M., Arefnia, K., Kourorian, Z., Rutherford, G. and McFarland, W. (2007) Insights from a Survey of Sexual Behavior among a Group of At-Risk Women in Tehran, Iran, 2006. AIDS Education \& Prevention, 19, 519-530. http://dx.doi.org/10.1521/aeap.2007.19.6.519

[16] World Health Organization AIDS Risk Behavior Assessment Questionnaire (ARBA).

[17] Hedayati-Moghaddam, M., Marjaneh, M.M. and Mashhadi, I.E. (2012) Knowledge and Attitudes of Physicians in Private Practice towards HIV/AIDS in Mashhad, Iran. International Journal of STD \& AIDS, 23, e11-e16. http://dx.doi.org/10.1258/ijsa.2009.009447

[18] Majdi, M., Khani, H., Azadmarzabadi, E., Montazeri, A., Hallajian, E., Babamahmodi, F. and Kariminasab, M.H. (2011) Knowledge, Attitudes and Practices towards HIV/AIDS among Iranian Prisoners in Mazandaran Province in the South-Coast Area of the Caspian Sea. Eastern Mediterranean Health Journal, 17, 904-910.

[19] Tavoosi, A., Zaferani, A., Enzevaei, A., Tajik, P. and Ahmadinezhad, Z. (2004) Knowledge and Attitude towards HIV/AIDS among Iranian Students. BMC Public Health, 4, 17.

[20] Yazdi, C., Aschbacher, K., Arvantaj, A., Naser, H., Abdollahi, E., Asadi, A., Mousavi, M., Narmani, M.R., Kianpishe, M., Nicfallah, F. and Moghadam, A.K. (2006) Knowledge, Attitudes and Sources of Information Regarding HIV/AIDS in Iranian Adolescents. AIDS Care, 18, 1004-1010. http://dx.doi.org/10.1080/09540120500526284

[21] Downing, S.M. (2004) Reliability: On the Reproducibility of Assessment Data. Medical Education, 38, $1006-1012$. http://dx.doi.org/10.1111/j.1365-2929.2004.01932.x

[22] Chahil-Graf, R. and Madani, N. (2014) Women, Culture and the HIV Epidemic in MENA. Journal of the International AIDS Society, 17, Article ID: 19074.

[23] Brener, N.D., Billy, J.O. and Grady, W.R. (2003) Assessment of Factors Affecting the Validity of Self-Reported Health-Risk Behavior among Adolescents: Evidence from the Scientific Literature. Journal of Adolescent Health, 33, 436-457. http://dx.doi.org/10.1016/S1054-139X(03)00052-1

[24] Anglewicz, P., Gourvenec, D., Halldorsdottir, I.,O’Kane, C., Koketso, O., Gorgens, M. and Toby, K. (2013) The Effect 
of Interview Method on Self-Reported Sexual Behavior and Perceptions of Community Norms in Botswana. AIDS and Behavior, 17, 674-687. http://dx.doi.org/10.1007/s10461-012-0224-Z

[25] Phillips, A.E., Gomez, G.B., Boily, M.-C. and Garnett, G.P. (2010) A Systematic Review and Meta-Analysis of Quantitative Interviewing Tools to Investigate Self-Reported HIV and STI Associated Behaviours in Low- and MiddleIncome Countries. International Journal of Epidemiology, 39, 1541-1555. http://dx.doi.org/10.1093/ije/dyq114 